\title{
New surgical horizons: the role of cytoreductive nephrectomy for metastatic kidney cancer
}

\author{
Ricardo A. Rendon, $M D$
}

\section{$\mathrm{R}$}

Abstract

Renal cell carcinoma is the most lethal urologic malignancy. Up to $30 \%$ of patients with kidney cancer have metastatic disease and $30 \%$ of those treated for local or locally advanced disease will progress to metastases. Radical nephrectomy is the standard treatment for the management of nondisseminated kidney cancer, but the role of cytoreductive nephrectomy for patients with metastatic disease is controversial. In this paper, the rationale for cytoreductive nephrectomy is described and the currently available evidence for and against it is evaluated. The different approaches to defining prognostic factors to select which patients will benefit from cytoreductive nephrectomy will also be described. Finally, the role of cytoreductive nephrectomy in the era of new targeted therapies is discussed. enal cell carcinoma (RCC) accounted for $3.0 \%$ of all new adult malignancies and $8.9 \%$ of all cancer deaths in Canada for the year 2006. ${ }^{1}$ Kidney cancer is the most lethal urologic malignancy; more than $34 \%$ of patients die of their disease. ${ }^{1}$ Close to $30 \%$ of patients have metastatic disease and $30 \%$ of patients diagnosed with local or locally advanced disease will ultimately progress to metastases. ${ }^{2}$

Patients with metastatic RCC have a poor prognosis; historically, survival is $73 \%$ at 6 months, $48 \%$ at 1 year, $27 \%$ at 2 years and $9 \%$ at 5 years. ${ }^{3}$ Over the last 2 decades, survival has improved, particularly for some subsets of patients with advanced disease. In 1978, it was reported that nephrectomy alone provided a minimal survival advantage for patients with metastatic disease. ${ }^{4}$ With the subsequent introduction of biological-response modifiers, cytoreductive nephrectomy $(\mathrm{CN})$ has been studied mostly retrospectively over the last 10-15 years. In this paper, I review this literature, describing the rationale for $\mathrm{CN}$, and evaluating the current evidence for and against its use. I also review the different approaches to selecting patients who will benefit from the surgery, and its role in the era of new targeted therapies.

\section{Rationale for cytoreductive nephrectomy}

Several arguments for and against the role of $\mathrm{CN}$ have been proposed (Table 1). The main objectives of $\mathrm{CN}$ are to enhance the response to systemic therapy and to improve quality of life. Additional gains from primary $\mathrm{CN}$ include the ability to confirm histology, more accurately assess the tumour stage and provide tissue for development of vaccine therapies. ${ }^{5,6}$

\section{Enhancement of response to systemic therapy}

The rationale for $\mathrm{CN}$ was initially founded on early reports of spontaneous regression of metastases after nephrectomy alone in up to $7 \%$ of cases. ${ }^{7}$ The actual incidence of spontaneous regression of RCC is unknown, since the denominator is rarely specified in these reports. In 1982, Snow and Schellhammer ${ }^{8}$ indicated that the incidence is less than $1 \%$ and that regression is a "fortuitous event rather than the rule." The mechanism for spontaneous regression is unclear, although immunologic factors have been implicated. Because most spontaneous regressions have been observed in the lungs, Freed and colleagues ${ }^{9}$ postulated that this organ has a large number of macrophages and lymphocytes, and a large amount of immunoglobulin that are suppressed until the primary tumour is removed. Another immunologic theory that supports $\mathrm{CN}$ implies that there might be a host immune dysfunction, and poor recognition and presentation of antigens..$^{10}$ It also has been postulated that cytokines and growth factors are released by the primary tumour and promote the growth of metastases that could be avoided through surgical removal of the renal mass. ${ }^{6}$

Other advantages of $\mathrm{CN}$ are the lack of response of the primary lesion to cytokine therapy, regardless of the grade of response at metastatic sites. The removal of the source of potential new metastases and the overall debulking of the tumoral mass has also been hypothesized as a possible benefit of $\mathrm{CN} .{ }^{11}$

\section{Improvement of quality of life}

The role of palliative nephrectomy is controversial. Traditional indications for it have been hematuria, pain and paraneoplastic syndromes (e.g., hypercalcemia, hypertension, fever, ane- 
mia). However, palliative nephrectomy carries a high risk of morbidity. Although nephrectomy is very effective for controlling hematuria, other less morbid procedures such as angioinfarction should be considered. Nephrectomy rarely alleviates pain, which is usually caused by direct involvement of nerves, muscles or bones.

Although, some patients experience an improvement in quality of life after the surgery, it is usually short-lived. Unless all metastatic deposits are also treated at the time of nephrectomy, paraneoplastic systemic manifestations of the disease do not improve, nor does the quality of life of the patient, which may instead deteriorate.

\section{Prognostic factors}

Patient selection is a key factor in determining whether survival is better achieved by initial $\mathrm{CN}$ or initial systemic therapy. Two factors must be considered: the patient's overall performance status and oncological prognosis. Several authors have demonstrated that patients with poor Eastern Cooperative Oncology Group performance status (ECOG PS) (Table 2) ${ }^{12}$ have a much worse prognosis when they undergo surgical management of advanced RCC. In their series of 84 patients, Mani and colleagues ${ }^{13}$ reported that those with an ECOG PS of 1 have a shorter median survival $(6 \mathrm{mo} \mathrm{v}$. 15.2 mo; $p<0.001$ ) than patients with an ECOG PS of 0 . Levy and colleagues ${ }^{14}$ demonstrated that through the strict selection of surgical candidates (ECOG $0-1)$, the vast majority $(91 \%)$ of patients were able to receive systemic therapy within 40 days. Another investigator ${ }^{15}$ reported similar findings using the Karnofsky Performance Status. In addition, in the European Organization for Research and Treatment of Cancer (EORTC) ${ }^{16}$ and the Southwest Oncology Group (SWOG) ${ }^{17}$ randomized trials, which included only patients with an ECOG PS of $0-1,98 \%$ of the patients went on to receive systemic treatment.

The group from Tufts University ${ }^{18}$ reviewed their experience before 1991 when most patients underwent $\mathrm{CN}$ before interleukin-2 (IL-2) administration. They identified several poor prognostic factors, including patients who had involvement of the central nervous system, or bone or liver metastases, poor pulmonary and cardiac function, or an ECOG PS of 2-3, or had resection of less that $75 \%$ of the tumour burden. Using these strict criteria, the authors reported their results for 28 patients who underwent initial CN. During the 5 -year period of this study, 57 other patients presented with metastatic disease, but had multiple reasons for surgical exclusion. One mortality occurred because of disease progression at 1 month and the remainder of the patients were able to receive IL-2 at a median start time of 1.5 months. The overall response rate was 39\%, much higher than that reported for any other contemporary series. These excellent results emphasize the need for appropriate patient selection.

\begin{tabular}{|c|c|}
\hline For & Against \\
\hline $\begin{array}{l}\text { Palliation of tumour complications } \\
\text { (pain, hematuria, paraneoplastic } \\
\text { syndromes) }\end{array}$ & $\begin{array}{l}\text { Other treatment alternatives for } \\
\text { palliation (embolization, ionic and } \\
\text { nonionic radiation therapies) }\end{array}$ \\
\hline $\begin{array}{l}\text { Potential spontaneous regression } \\
\text { of metastases }\end{array}$ & Rare spontaneous regression \\
\hline Debulking of tumour volume & Risk of perioperative mortality \\
\hline $\begin{array}{l}\text { Removal of source of new } \\
\text { metastases }\end{array}$ & Risk of perioperative morbidity \\
\hline $\begin{array}{l}\text { Improvement of host immune } \\
\text { dysfunction }\end{array}$ & $\begin{array}{l}\text { Adverse effect on immune } \\
\text { system and promotion of tumour } \\
\text { growth }\end{array}$ \\
\hline $\begin{array}{l}\text { Improvement of performance } \\
\text { status }\end{array}$ & $\begin{array}{l}\text { Risk of delayed or no initiation of } \\
\text { systemic therapy }\end{array}$ \\
\hline $\begin{array}{l}\text { Lack of response of primary } \\
\text { lesion to immunotherapy }\end{array}$ & $\begin{array}{l}\text { Better response of primary lesion } \\
\text { to new targeted agents }\end{array}$ \\
\hline Confirm histology and stage & \\
\hline
\end{tabular}

Table 2: Eastern Cooperative Oncology Group (ECOG) performance status (PS) ${ }^{12}$

\section{ECOG Performance Status*}

Grade ECOG

0 Fully active, able to carry on all pre-disease performance without restriction

1 Restricted in physically strenuous activity but ambulatory and able to carry out work of a light or sedentary nature, e.g., light house work, office work

2 Ambulatory and capable of all selfcare but unable to carry out any work activities. Up and about more than $50 \%$ of waking hours

3 Capable of only limited selfcare, confined to bed or chair more than $50 \%$ of waking hours

4 Completely disabled. Cannot carry on any selfcare. Totally confined to bed or chair

$5 \quad$ Dead

Reprinted with permission from the Eastern Cooperative Oncology Group (Robert Comis MD, Group Chair). 
Other authors have also demonstrated that sarcomatoid histology, ${ }^{19}$ nuclear differentiation Fuhrman grade 4 and recent weight loss $^{13}$ are poor prognostic factors for $\mathrm{CN}$. Serum C-reactive protein level ${ }^{20}$ and erythrocyte sedimentation rate $^{21}$ have been described as prognostic factors in multivariate analyses.

Several attempts to develop prediction nomograms for RCC have been made. ${ }^{22-25}$ These predictive nomograms include the standard clinical and pathological features described above. The arrival and application of new targeted therapies necessitate a re-evaluation of the current prognostic systems to incorporate emerging molecular markers within existing clinical and pathologic staging constructs. Recent molecular characterization has identified prognostic factors such as carbonic anhydrase IX and the phosphatase and tensin homologue. ${ }^{26}$ The International Kidney Cancer Working Group is currently developing a comprehensive database from large centres that treat patients with metastatic RCC. This database will be used to develop a set of prognostic factors derived from a single model that should perform better than multiple predictive models developed by single institutions.

In their attempt to choose the ideal patient candidate, some authors have made their selection criteria for $\mathrm{CN}$ before systemic therapy very strict.
In fact, Bromwich and colleagues ${ }^{27}$ reported that, with their protocol, only a small proportion $(21 \%)$ of all the patients who had metastatic disease at their institution were suitable candidates for $\mathrm{CN}$.

\section{Retrospective series}

In the evaluation of the role of $\mathrm{CN}$ before systemic therapy, 2 questions must be resolved. Does removal of the primary tumour enhance the response of systemic therapy in metastatic sites and thus improve survival and or quality of life? Is the morbidity and mortality potential of $\mathrm{CN}$ low enough to allow patients to receive systemic therapy in a timely fashion? Several centres have attempted to answer these questions in their publications about their individual experiences with $\mathrm{CN}$ before systemic therapy (Table 3) $28-36$ Unfortunately, our ability to provide a definitive answer to these questions has been hampered by the small sample sizes and retrospective nature of these studies. ${ }^{11,37}$ Overall, most of these series (see Table 3) demonstrate that in experienced hands, those patients who undergo $\mathrm{CN}$ before immunotherapy tend to have better outcomes than patients who do not undergo $\mathrm{CN}$, while maintaining an acceptable perioperative mortality $(0 \%-17 \%)$ and morbidity $(13 \%-50 \%)$.

Table 3. Cytoreductive nephrectomy as a multimodality treatment: the series

\begin{tabular}{|c|c|c|c|c|c|c|c|c|}
\hline \multirow[b]{2}{*}{ Series } & \multirow{2}{*}{$\begin{array}{l}\text { Type } \\
\text { of } \\
\text { study }\end{array}$} & \multicolumn{2}{|c|}{ Group, no. of patients } & \multirow{2}{*}{$\begin{array}{c}\text { Operative } \\
\text { mortality, } \\
\%\end{array}$} & \multirow{2}{*}{$\begin{array}{c}\text { Surgical } \\
\text { morbidity, } \\
\%\end{array}$} & \multirow{2}{*}{$\begin{array}{l}\text { Unable to } \\
\text { receive } \\
\text { systemic } \\
\text { therapy, \% }\end{array}$} & \multirow{2}{*}{$\begin{array}{l}\text { Time to } \\
\text { systemic } \\
\text { therapy, d }\end{array}$} & \multirow{2}{*}{$\begin{array}{c}\text { Response } \\
\text { rate, \% }\end{array}$} \\
\hline & & $\mathrm{RN}$ & NRN & & & & & \\
\hline Wolf et $\mathrm{al}^{29}$ & $\mathrm{R}$ & 23 & 0 & 0.0 & 16.0 & 26.1 & NR & 13.0 \\
\hline Bennett et $\mathrm{al}^{30}$ & $\mathrm{R}$ & 30 & 0 & 17.0 & 50.0 & 77.0 & NR & 13.3 \\
\hline Mani et $\mathrm{al}^{13}$ & $\mathrm{R}$ & 58 & 26 & NR & NR & NR & NR & $0.0-7.0$ \\
\hline Walther et $\mathrm{al}^{32}$ & $\mathrm{R}$ & 195 & 51 & 1.0 & 13.0 & 38.0 & NR & 6.0 \\
\hline Fallick et $a 1^{18}$ & $\mathrm{R}$ & 28 & 0 & 3.6 & NR & 7.1 & 45 & 39.3 \\
\hline Figlin et $\mathrm{al}^{33}$ & $\mathrm{R}$ & 62 & 0 & 0.0 & NR & 11.0 & NR & 34.5 \\
\hline Levy et $\mathrm{al}^{14}$ & $\mathrm{R}$ & 66 & 0 & 3.0 & 35.0 & 18.1 & 40 & $N R$ \\
\hline Tigrani et $\mathrm{al}^{34}$ & $\mathrm{R}$ & 63 & 0 & 3.6 & 14.0 & 27.0 & NR & NR \\
\hline Mosharafa et al ${ }^{36}$ & $\mathrm{R}$ & 32 & 0 & 3.0 & 16.0 & $N R$ & 116 & NR \\
\hline
\end{tabular}


In these series ${ }^{28-36}$ the number of patients who were unable to receive immunotherapy after $\mathrm{CN}$ because of surgical complications and or disease progression varied from $7.1 \%$ to $77.0 \%$. The time to initiation of immunomodulators, although not frequently reported, ranged between 40 and 116 days. The overall response rates varied significantly $(6.0 \%-39.3 \%)$, mostly because of differences in patient-selection criteria.

Although these retrospective studies ${ }^{28-36}$ provide no definitive answers to the previously stated questions, great insight into patient selection and identification of prognostic factors has been gained, both from the medical or surgical and oncological points of view.

\section{Prospective series}

From the results of clinical research conducted up until 2001, the outcomes for patients who underwent $\mathrm{CN}$ are better understood, but evidence of its ability to prolong survival has remained inconclusive. To better understand the role of $\mathrm{CN}$ for patients with metastatic disease, 2 randomized controlled trials ${ }^{16,17}$ were performed. Patients in both trials were randomized to immunotherapy with interferon- $\alpha 2 b$ with or without prior nephrectomy. The EORTC trial ${ }^{16}$ accrued 85 patients in total. Although this trial was underpowered, patients in the nephrectomy arm survived for 17 months compared with only 7 months for the immunotherapy-only group. Time to progression of the disease improved in the nephrectomy group, compared with the control (5 mo v. 3 mo). The SWOG trial, ${ }^{17}$ which randomized 246 patients with the same entry criteria as those in the EORTC trial, ${ }^{16}$ reported an improvement in median survival of 11.1 months for the nephrectomy group compared with 8.1 months for the control group. In the nephrectomy group, more patients had a good performance status, but this variable did not affect survival, when evaluated with multivariate analysis.

Because of the similarities of the patient population in these 2 studies, a pooled analysis of the EORTC ${ }^{16}$ and SWOG $^{17}$ studies was performed. ${ }^{38}$ This analysis reported results for 331 patients. The median survival was 13.6 months for the nephrectomy plus interferon arm and 7.8 months for the interferon-only group, representing a $31 \%$ decrease in the risk of death $(p=0.002)$. Most important- ly, most patients $(98 \%)$ in both studies were able to receive systemic therapy, and their surgical mortality and morbidity were very low (Table 3). Unfortunately, these 2 studies failed to report information about the quality of life of the extra months gained and did not address the issue of surgical timing (i.e., whether $\mathrm{CN}$ should be done before or after systemic treatment).

\section{Other surgical options}

\section{Laparoscopic cytoreductive nephrectomy}

Increasingly, laparoscopic nephrectomy is being used for the management of localized and locally advanced RCC, and has become the standard of care for the majority of these procedures. ${ }^{39,40}$ The obvious advantages of laparoscopic surgery, such as reduced morbidity and faster recovery, should easily transfer to the metastatic population. Several series have reported that in wellselected cases, laparoscopic $\mathrm{CN}$ is feasible and safe. Rabets and colleagues, ${ }^{41}$ in their series of 22 patients who underwent laparoscopic $\mathrm{CN}$ reported that their results compared favourably with those for open surgery; they had a shorter operative time (40 min), less blood loss (by $940 \mathrm{~mL}$ ) and a shorter hospital stay (by $3.8 \mathrm{~d}$ ). However, tumours were larger in the open group $(9.5 \mathrm{~cm} \mathrm{v}$. $7.9 \mathrm{~cm} ; p<0.04)$. In their series, Walther and colleagues ${ }^{42}$ reported that the time to starting systemic therapy was significantly decreased ( $36 \mathrm{~d}$ v. $61 \mathrm{~d}$; $p<0.01)$ in the laparoscopic group. In the largest series reported to date, Matin and colleagues ${ }^{43}$ reported that the laparoscopic cohort had less blood loss and decreased hospital stay, and no differences in complications, surgical time and time to initiation of systemic therapy compared with the open-surgery cohort. These results should be interpreted cautiously because the groups of patients included in the laparoscopic $\mathrm{CN}$ cohorts tended to have smaller tumours and lower-stage disease than historical or contemporary cohorts of patients who underwent open $\mathrm{CN}$. The results of all these series demonstrate that when a patient is appropriately selected by a surgeon with suitable skills and experience, laparoscopic $\mathrm{CN}$ is feasible and safe. In fact, it has the potential advantage of less bleeding, and shorter hospital stay and convalescence. 


\section{Nephron-sparing surgery}

In some selected cases, radical nephrectomy in patients with metastatic disease is not always indicated because they have renal dysfunction, RCC in a single kidney or bilateral renal masses. In these cases, nephron-sparing cytoreductive surgery has been done. Wolf and colleagues ${ }^{29}$ reported the outcomes for 25 patients who underwent surgical cytoreduction, including 3 patients who underwent nephron-sparing $\mathrm{CN}$, but did not differentiate outcomes by type of procedure. Krambeck and colleagues ${ }^{44}$ compared the results of their series of 16 patients who underwent nephron-sparing surgery for $\mathrm{pM} 1 \mathrm{RCC}$ with those for a retrospective cohort of 404 patients who underwent radical nephrectomy for the same-stage disease. Comparable to the results for that cohort, the reported cancer-specific survival at 1, 3 and 5 years for the patients who underwent nephron-sparing surgery was $81 \%, 49 \%$ and $49 \%$, respectively. Patients who underwent partial nephrectomy were more likely to have early (33\% v. $10 \% ; p=0.009)$ and late $(50 \%$ v. $19 \% ; p=0.018)$ complications than patients who underwent radical nephrectomies. The authors did not find differences in complication rates for patients who underwent partial nephrectomies for stage pM1 RCC and their retrospective cohort of 139 patients with stage $\mathrm{pM} 0$ RCC. The authors concluded that oncological outcomes were similar for partial and radical nephrectomy, and that early and late complication rates for these surgeries do not vary from those for stage pM0 nephron-sparing surgeries, with the added benefit of renal-function preservation.

\section{Cytoreductive nephrectomy in the era of targeted therapies}

As thoroughly discussed elsewhere in this supplement, new antivascular targeted therapies have shown excellent objective responses in both metastatic disease and primary tumours, but no complete responses have been observed to date. The majority of these well-controlled trials accrued mostly patients who underwent $\mathrm{CN}$ before receiving systemic therapy. Integration of new targeted agents and $\mathrm{CN}$ needs further evaluation because no valid scientific evidence about the added benefits of $\mathrm{CN}$ in conjunction with the use of targeted agents is available. There are currently several phase 2 studies being conducted to evaluate the ideal timing of $\mathrm{CN} .{ }^{45}$ Currently, there are ongoing discussions in Europe about the development of a randomized trial to determine the real need for $\mathrm{CN}$ with the new targeted agents (Dr. Bernard Escudier, Institut Gustave Roussy, Paris, France: personal communication, 2006 Dec 12). Although a randomized trial would provide the best evidence, some clinicians have raised concerns about the low feasibility of conducting such a study in the face of a rapidly evolving field and a limited number of patients. In the meantime, because of the strong evidence of the benefit of $\mathrm{CN}$ during the cytokine era, it makes sense to continue to do $\mathrm{CN}$ for appropriate candidates.

\section{Conclusions}

The current management of metastatic RCC is evolving rapidly, particularly because of improvement in systemic therapy. These rapid changes have created areas of uncertainty that make decision making very challenging for clinicians. More than ever, the treatment of metastatic RCC requires a multidisciplinary approach.

Over the last 20 years, several centres have reported their experience with initial or delayed $\mathrm{CN}$. Most of these series have demonstrated improvements in survival and delay in tumour progression. All these series comprise retrospective reviews of very heterogeneous populations. Only 2 prospective randomized trials ${ }^{16,17}$ have demonstrated the importance of $\mathrm{CN}$, but these trials did not evaluate whether surgery should be performed before or after systemic therapy. In addition to this problem, cytokine therapy was the only treatment available at the time these trials were conducted; therefore, currently no data exist about the role of $\mathrm{CN}$ alone or in conjunction with potentially useful neoadjuvant and adjuvant therapy in the era of targeted agents. A large randomized trial has been proposed in Europe, but its results will not be available for years. In the meantime, decisions about whether patients should undergo $\mathrm{CN}$ must be made. Based on the good results observed in the randomized interferon- $\alpha$ trials $\mathrm{s}^{16,17}$ and the lack of complete responses with any of the new targeted treatments, it is my opinion and that of others that nephrectomies should continue to be performed as part of a multidisciplinary integrated strategy. Most patients with metastatic RCC should be considered for initial CN. Patients who are poor 
surgical candidates because of comorbidities and patients who have high-risk disease, such as multiple metastases, metastases to the central nervous system, spine and liver, Fuhrman grade 4 disease, and sarcomatoid histology, should receive upfront systemic therapy, and consolidation surgery should be considered, based on response to the treatment. In addition, patients who pose a complex surgical scenario (e.g., encasement of the superior mesenteric artery) should also receive primary systemic therapy. Palliative surgery is justified, but rarely indicated when other forms of local treatment such as angioinfarction have failed or are not indicated.

Laparoscopic $\mathrm{CN}$ has proven to be safe and feasible in well-selected candidates and seems to decrease the amount of blood loss, hospital stay and recovery time. These benefits should not be used as a rationale to indiscriminately perform $\mathrm{CNs}$ because the oncological outcomes are the same, regardless of the surgical technique chosen.

Finally, because of the outlined challenges, better and more accurate prognostic markers are clearly needed. All these patients should be considered for inclusion in clinical trials.

From the Department of Urology, Dalhousie University and Queen Elizabeth II Health Sciences Centre, Halifax, NS.

This article has been peer reviewed.

Competing interests: None declared.

\section{References}

1. Canadian Cancer Society - National Cancer Institute of Canada. Canadian Cancer Statistics 2006. Toronto, Canada, 2006.

2. Lam JS, Shvarts 0, Leppert JT, et al. Renal cell carcinoma 2005: new frontiers in staging, prognostication and targeted molecular therapy. J Urol 2005;173:1853-62.

3. Maldazys JD, deKernion JB. Prognostic factors in metastatic renal carcinoma. J Urol 1986;136:376-9.

4. Dekernion JB, Ramming KP, Smith RB. The natural history of metastatic renal cell carcinoma: a computer analysis. J Urol 1978;120:148-52.

5. Sengupta S, Leibovich BC, Blute ML, et al. Surgery for metastatic renal cell cancer. World J Urol 2005;23:155-60.

6. Mickisch GH, Mattes RH. Combination of surgery and immunotherapy in metastatic renal cell carcinoma. World J Urol 2005;23:191-5.

7. Oliver RT, Nethersell AB, Bottomley JM. Unexplained spontaneous regression and alphainterferon as treatment for metastatic renal carcinoma. Br J Urol 1989;63:128-31.

8. Snow RM, Schellhammer PF. Spontaneous regression of metastatic renal cell carcinoma. Urology 1982;20:177-81.

9. Freed SZ, Halperin JP, Gordon M. Idiopathic regression of metastases from renal cell carcinoma. J Urol 1977;118:538-42.

10. $\mathrm{Ng}$ CS, Novick AC, Tannenbaum CS, et al. Mechanisms of immune evasion by renal cell carcinoma: tumor-induced T-lymphocyte apoptosis and NFkappaB suppression. Urology 2002:59:9-14.

11. Wood CG. The role of cytoreductive nephrectomy in the management of metastatic renal cell carcinoma. Urol Clin North Am 2003;30:581-8.

12. Oken MM, Creech RH, Tormey DC, et al. Toxicity and response criteria of the Eastern Cooperative Oncology Group. Am J Clin Oncol 1982;5:649-55.

13. Mani S, Todd MB, Katz K, et al. Prognostic factors for survival in patients with metastatic renal cancer treated with biological response modifiers. J Urol 1995;154:35-40.

14. Levy DA, Swanson DA, Slaton JW, et al. Timely delivery of biological therapy after cytoreductive nephrectomy in carefully selected patients with metastatic renal cell carcinoma. J Urol 1998;159:1168-73.

15. Russo P. Surgical intervention in patients with metastatic renal cancer: current status of metastasectomy and cytoreductive nephrectomy. Nat Clin Pract Urol 2004; 1:26-30.

16. Mickisch GH, Garin A, van Poppel H, et al. Radical nephrectomy plus interferon-alfabased immunotherapy compared with interferon alfa alone in metastatic renal-cell carcinoma: a randomised trial. Lancet 2001;358:966-70.

17. Flanigan RC, Salmon SE, Blumenstein BA, et al. Nephrectomy followed by interferon alfa-2b compared with interferon alfa-2b alone for metastatic renal-cell cancer. $N$ Engl J Med 2001;345:1655-9.

18. Fallick ML, MCDermott DF, LaRock D, et al. Nephrectomy before interleukin-2 therapy for patients with metastatic renal cell carcinoma. J Urol 1997;158:1691-5.

19. Cangiano T, Liao J, Naitoh J, et al. Sarcomatoid renal cell carcinoma: biologic behavior, prognosis, and response to combined surgical resection and immunotherapy. J Clin Oncol 1999; 17:523-8.

20. Fujikawa K, Matsui Y, Oka H, et al. Serum C-reactive protein level and the impact of cytoreductive surgery in patients with metastatic renal cell carcinoma. J Urol 1999; 162:1934-7.

21. Lee SE, Byun SS, Han JH, et al. Prognostic significance of common preoperative laboratory variables in clear cell renal cell carcinoma. BJU Int 2006;98:1228-32.

22. Cindolo L, de la Taille A, Messina G, et al. A preoperative clinical prognostic model for non-metastatic renal cell carcinoma. BJU Int 2003;92:901-5.

23. Kattan MW, Reuter V, Motzer RJ, et al. A postoperative prognostic nomogram for renal cell carcinoma. J Urol 2001;166:63-7.

24. Frank I, Blute ML, Cheville JC, et al. An outcome prediction model for patients with clear cell renal cell carcinoma treated with radical nephrectomy based on tumor stage, size, grade and necrosis: the SSIGN score. J Urol 2002;168:2395-400.

25. Zisman A, Pantuck AJ, Dorey F, et al. Improved prognostication of renal cell carcinoma using an integrated staging system. J Clin Oncol 2001;19:1649-57.

26. Lam JS, Leppert JT, Belldegrun AS, et al. Adjuvant therapy of renal cell carcinoma: patient selection and therapeutic options. BJU Int 2005; 96 :483-8.

27. Bromwich E, Hendry D, Aitchison M. Cytoreductive nephrectomy: is it a realistic option in patients with renal cancer? BJU Int 2002;89:523-5.

28. Rackley R, Novick A, Klein E, et al. The impact of adjuvant nephrectomy on multimodality treatment of metastatic renal cell carcinoma. J Urol 1994;152:1399-403.

29. Wolf JS Jr, Aronson FR, Small EJ, et al. Nephrectomy for metastatic renal cell carcinoma: a component of systemic treatment regimens. J Surg Oncol 1994;55:7-13.

30. Bennett RT, Lerner SE, Taub HC, et al. Cytoreductive surgery for stage IV renal cell carcinoma. J Urol 1995; 154:32-4.

31. Franklin JR, Figlin R, Rauch J, et al. Cytoreductive surgery in the management of metastatic renal cell carcinoma: the UCLA experience. Semin Urol Oncol 1996;14:230-6.

32. Walther MM, Yang JC, Pass HI, et al. Cytoreductive surgery before high dose interleukin-2 based therapy in patients with metastatic renal cell carcinoma. J Urol 1997; 158:1675-8.

33. Figlin RA, Pierce WC, Kaboo R, et al. Treatment of metastatic renal cell carcinoma with nephrectomy, interleukin-2 and cytokine-primed or CD8(+) selected tumor infiltrating lymphocytes from primary tumor. J Urol 1997; 158:740-5.

34. Tigrani VS, Reese DM, Small EJ, et al. Potential role of nephrectomy in the treatment of metastatic renal cell carcinoma: a retrospective analysis. Urology 2000;55: 36-40.

35. Pantuck AJ, Belldegrun AS, Figlin RA. Nephrectomy and interleukin-2 for metastatic renal-cell carcinoma. N Engl J Med 2001;345:1711-2.

36. Mosharafa A, Koch M, Shalhav A, et al. Nephrectomy for metastatic renal cell carcinoma: Indiana University experience. Urology 2003;62:636-40.

37. Flanigan RC. Debulking nephrectomy in metastatic renal cancer. Clin Cancer Res 2004; 10:6335S-41S 
38. Flanigan RC, Mickisch G, Sylvester R, et al. Cytoreductive nephrectomy in patients with metastatic renal cancer: a combined analysis. J Urol 2004;171:1071-6.

39. Saika T, Ono Y, Hattori R, et al. Long-term outcome of laparoscopic radical nephrectomy for pathologic T1 renal cell carcinoma. Urology 2003;62:1018-23.

40. Varkarakis IM, Bhayani SB, Allaf ME, et al. Laparoscopic-assisted nephrectomy with inferior vena cava tumor thrombectomy: preliminary results. Urology 2004;64:925-9.

41. Rabets JC, Kaouk J, Fergany A, et al. Laparoscopic versus open cytoreductive nephrectomy for metastatic renal cell carcinoma. Urology 2004;64:930-4.

42. Walther MM, Lyne JC, Libutti SK, et al. Laparoscopic cytoreductive nephrectomy as preparation for administration of systemic interleukin-2 in the treatment of metastatic renal cell carcinoma: a pilot study. Urology 1999;53:496-501.
43. Matin SF, Madsen LT, Wood CG. Laparoscopic cytoreductive nephrectomy: the M. D. Anderson Cancer Center experience. Urology 2006;68:528-32.

44. Krambeck $\mathrm{AE}$, Leibovich $\mathrm{BC}$, Lohse $\mathrm{CM}$, et al. The role of nephron sparing surgery for metastatic (pM1) renal cell carcinoma. [discussion 1995]. J Urol 2006;176:1990-5.

45. Jonasch E. Presurgical therapy in metastatic renal cell carcinoma. Expert Rev Anticancer Ther 2007;7:73-8

Correspondence: Dr. Ricardo A. Rendon, QEll Health Sciences Centre, Rm. 210, 5-South, Victoria Building, 1278 Tower Rd., Halifax NS B3H 2Y9; rrendon@dal.ca

\title{
We welcome your comments on the journal and on specific articles.
}

\author{
All letters will be considered \\ for publication in the journal.
}

\section{Send your letters to the Editor-in-Chief at journal@cua.org}

Evaluating the endoscopic treatment of

CUAJ JAUC

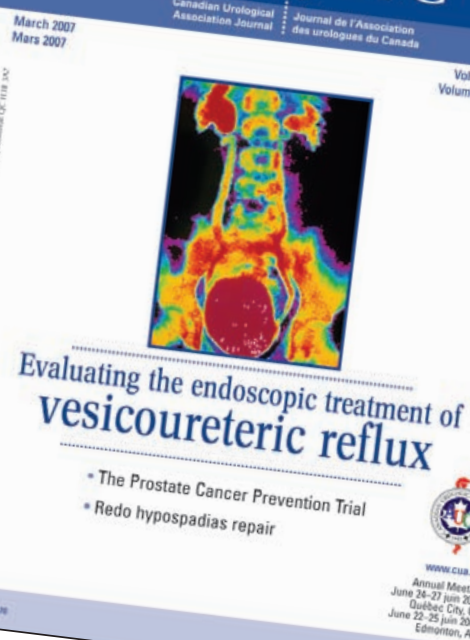

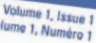

